\title{
ESCOLA NACIONAL DE FORMAÇÃO E APERFEIÇOAMENTO DE MAGISTRADOS (BRASIL) E INSTITUTO NACIONAL DE ESTUDOS JUDICIÁRIOS (ANGOLA): HISTÓRIAS, PERSPECTIVAS E DESAFIOS
}

\author{
NATIONAL SCHOOL OF TRAINING AND IMPROVEMENT \\ OF MAGISTRATES (BRAZIL) AND NATIONAL \\ INSTITUTE OF JUDICIAL STUDIES (ANGOLA): STORIES, \\ PERSPECTIVES AND CHALLENGES
}

MARCUS VINÍCIUS PEREIRA JÚNIOR

Docente do PPGPD/Enfam, da Esmarn, da Escola Judicial Eleitoral - TRE-RN e da UFRN. Doutor em ciências sociais - UFRN. Mestre em direito - UFRN. Especialista em infância e juventude - UFRN, Ministério Público e cidadania - UnP e direito processual civil - Universidade Gama Filho/RJ. Licenciado em filosofia - UFRN. Juiz de direito do TJRN. https://orcid.org/0000-0002-7797-903X

ARTUR DOMINGOS GUNZA Discente do PPGPD/Enfam. Membro do Conselho Superior da Magistratura Judicial de Angola. Diretor-Geral do Inej. Juiz desembargador do Tribunal da

Relação de Benguela (Angola). https://orcid.org/0000-0002-3706-9322

\section{RESUMO}

O artigo analisa as formações das magistraturas brasileira e angolana, destacando que fazem parte da abordagem as atuações da Escola Nacional de Formação e Aperfeiçoamento de Magistrados - Enfam (Brasil) e do Instituto Nacional de Estudos Judiciários - Inej (Angola), utilizando a metodologia de revisão bibliográfica e pesquisa documental. Assim, foram identificados pontos em comum, como as missões de promover a preparação e o aperfeiçoamento de magistrados, ressaltando, porém, que o Inej participa diretamente dos concursos para a seleção de novos magistrados, o que não ocorre com a Enfam, pois no Brasil os concursos públicos são realizados diretamente por parte dos tribunais aos quais os novos magistrados serão vinculados. Concluiu-se que o Programa de Pós-Graduação Profissional em Direito 
desenvolvido pela Enfam é um marco histórico para as escolas de magistratura no mundo, na medida em que possibilita a análise de problemas e soluções de maneira científica.

Palavras-chave: formação de magistrados; Enfam; Inej; Brasil; Angola.

\begin{abstract}
The article analyzes the formations of the Brazilian and Angolan magistrates, highlighting that the actions of Enfam (Brazil) and Inej (Angola) are part of the study, using the methodology of bibliographic review and documentary research. Thus, common points were identified, such as the missions to promote the preparation and improvement of magistrates, emphasizing, however, that Inej participates directly in the selection of new magistrates, which is not the case with Enfam, as in Brazil public selection processes are conducted directly by the Courts to which the new magistrates will be set in. It was concluded that the Professional Post-Graduation Program in Law developed by Enfam is a historic landmark for magistracy schools in the world, as it allows the analysis of problems and solutions in a scientific way.
\end{abstract}

Keywords: formation of magistrates; Enfam; Inej; Brazil; Angola.

Recebido: $25-5-2021$

Aprovado: 28-6-2021

\title{
SUMÁRIO
}

1 Introdução. 2 Escola Nacional de Formação e Aperfeiçoamento de Magistrados - Enfam: abordagem histórica e atual. 3 Instituto Nacional de Estudos Judiciários - Inej: abordagem histórica e atual. 4 Conclusão. Referências.

\section{INTRODUÇÃO}

Partindo da perspectiva de que a Escola Nacional de Formação e Aperfeiçoamento de Magistrados - Enfam é o órgão oficial de treinamento de juízes de direito e juízes federais brasileiros, conveniada com vários países, dentre eles a Angola, através do Protocolo de Cooperação n. 003/2018 (ESCOLA NACIONAL DE FORMAÇÃO E APERFEIÇOAMENTO DE MAGISTRADOS; ANGOLA, 2018), firmado 
com o Instituto Nacional de Estudos Judiciários - Inej, instituição vinculada ao Ministério da Justiça e dos Direitos Humanos de Angola, que tem a responsabilidade de formar magistrados, tanto judiciais quanto do Ministério Público', bem como escrivães, oficiais de diligências e outros, surgiu a necessidade de estudar as histórias, as perspectivas e os desafios da Enfam e do Inej.

Ressalte-se, ainda, que a aprovação do Juiz Desembargador Artur Domingos Gunza², na seleção para discentes do Mestrado Profissional em Direito e Poder Judiciário da Enfam, em meados de 2020, durante a Gestão do Ministro Antonio Herman Benjamin, então diretor-geral da Enfam, concretizou mais ainda as intenções firmadas no protocolo de cooperação acima referido, tornando o estudo necessário e útil, com o fim de estreitar as relações entre as magistraturas do Brasil e da Angola, bem como estimular o constante diálogo e aprendizado entre as magistraturas de todo o mundo, especialmente dos países de língua portuguesa.

Assim, o estudo acerca da Escola Nacional de Formação e Aperfeiçoamento de Magistrados e do Instituto Nacional de Estudos Judiciários pressupõe a compreensão da formação das duas nações de colonização portuguesa como forma de demonstrar o quanto uma pode ajudar no desenvolvimento da outra, na medida em que certamente muitos problemas são comuns, diferenciando, possivelmente, o período a ser observado.

Nesse contexto, é imperioso afirmar que as formações do Brasil e da Angola são frutos das Grandes Navegações, ocorridas na chamada Época dos Descobrimentos, em que contava muito a sorte do navegador, explicada pelo autor português Pedro Almeida Vieira (2015, p. 15) como a necessidade de sobreviver e saber se, antes ou depois de uma tempestade, vivo ou morto se ficava. Vieira (2015, p. 15-16) assim tratou a sorte no período do início das navegações que chegaram até o Brasil:

E desmesurada sorte, no decurso de tempestades e depois delas, teve Pedro Álvares Cabral após levantar âncora da praia de Belém, em Lisboa, nos primeiros

\footnotetext{
Acerca da magistratura em Angola, importa esclarecer, inicialmente, nos termos do Decreto Presidencial n. 84/2015, que os magistrados, judicial e do Ministério Público, selecionados no mesmo concurso público, são formados e capacitados pelo Inej, apesar da existência de estatutos distintos.

2 Atual diretor-geral do Inej, com início do mandato em 2020.
} 
dias de março de 1500. Capitaneando uma armada com cerca de milhar e meio de marujos, além de gentes da marinha, devia ele arribar em Sofala para visitar, em seguida, diversos soberanos da costa das Índias. O rei D. Manuel I pretendia fortalecer laços diplomáticos com as gentes daquelas terras e ali criar feitorias. Era ousada aventura marítima, embora já não inédita. Em todo o caso, mereceu esta viagem a devida pompa à saída de Lisboa, com bênção e missa celebrada pelo bispo de Ceuta.

Pelas lições acima transcritas, observa-se claramente que a ocupação portuguesa no Brasil foi iniciada pela sorte do navegador português Pedro Álvares Cabral, por volta de março de 1500, em período aproximado da ocupação ocorrida em Angola, como destacado em publicação do Movimento Popular de Libertação de Angola - MPLA (1965, p. 10), ao tratar de período correspondente ao ano de 1490, referindose ao início das relações entre Portugal e os povos que ocupavam o território onde atualmente está localizada Angola:

Os navios traziam artigos de comércio, presentes do Rei de Portugal ao Rei do Kongo ${ }^{3}$, alguns pedreiros para ajudarem na construção de uma Igreja e do Palácio do Rei Nkuvu e alguns padres franciscanos. Os navios voltaram para Portugal levando escravos, marfim e tecidos do Kongo feitos pelos artesãos. Esses tecidos feitos de fibras eram muito bonitos e bons.

A grande diferença entre as ocupações portuguesas no Brasil e em Angola pode ser descrita como a construção de relações entre o Rei de Portugal e o Rei do Kongo, no caso de Angola, através de trocas formais, como referido anteriormente, em que o português presenteou o angolano com ajuda para as construções de uma igreja e do Palácio do Rei Nkuvu, recebendo, em troca, escravos, marfim e tecidos. No caso do Brasil, as trocas, denominadas escambo, ocorreram diretamente com os índios, que ofertavam madeira e outros utensílios artesanais, recebendo machados, facas, espelhos, canivetes, dentre outros.

\footnotetext{
$\overline{3}$ Importa ressaltar que o atual território de Angola já foi dividido em reinos do Congo, sendo eles: Ndongo, Bailundo, Kassanje, Matamba, Chiyaka, Ndulu e Chingolo. Ressalte-se que atualmente o país é dividido em 18 províncias com características étnico-linguísticas bem distintas, que são as seguintes: Benguela, Bengo, Bié, Cabinda, Cunene, KuanzaNorte, Kuanza-Sul, Kuando-Kubango, Malange, Moxico, Namibe, Luanda, Luanda-Norte, Luanda-Sul, Huambo, Huila, Uige e Zaire.
} 
Passado o período das grandes navegações, no qual foram estabelecidas as primeiras relações entre Portugal e as terras "descobertas", Brasil e Angola, mostra-se fundamental destacar que, apesar do início da aproximação entre Portugal e os nativos dos referidos territórios ter ocorrido em período aproximado, com a transformação em colônias portuguesas, por diversos fatores históricos, as independências ocorreram em períodos totalmente distintos. No Brasil, foi em 7 de setembro de 1822, e em Angola, adveio em 11 de novembro de 19754.

A diferença de aproximadamente 153 anos entre as independências do Brasil e da Angola, respectivamente, refletem diretamente na formação da magistratura nas referidas nações, ressaltando que, no Brasil, de acordo com dados extraídos do sítio do Conselho Nacional de Justiça (CNJ) ([2021]), as instituições judiciárias tiveram início com a colonização portuguesa, após designação dos juízes ordinários, almotacés e outros funcionários indicados pelos donatários das capitanias hereditárias.

A vinda da família real portuguesa para o Brasil foi um fator histórico extremamente importante para a independência do Brasil, tendo refletido diretamente na formação da magistratura, conforme se observa com a informação também extraída no sítio do CNJ, adiante transcrita, fazendo referência, inclusive, à criação do Supremo Tribunal de Justiça, após a independência do Brasil:

Em 1808, com a vinda da família real portuguesa para o Brasil, a Relação do Rio de Janeiro foi transformada em Casa da Suplicação pelo alvará régio de 10 de maio daquele ano, equiparado hierarquicamente à Casa de Suplicação de Lisboa. Pela importância, essa data tornou-se o Dia da Memória do Poder Judiciário.

Depois da independência do Brasil, em 1822, a Constituição do Império de 1824 determinou a criação do Supremo Tribunal de Justiça, instalado em 1829. (CONSELHO NACIONAL DE JUSTIÇA, [2021])

Nesse contexto, observa-se que a vinda da família real para o Brasil foi fator determinante para a independência e, consequentemente, a formação de um Judiciário autônomo, inicialmente com base na

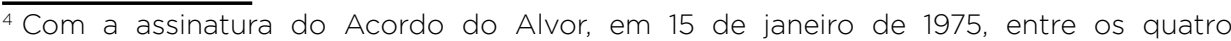
intervenientes no conflito existente no território onde atualmente é denominado Angola, Governo português, Frente Nacional de Libertação de Angola - FNLA, Movimento pela Liberação de Angola - MPLA e União Nacional para a Independência Total de Angola Unita. No acordo, ficou marcada a independência e a passagem da soberania para o dia 11 de novembro deste ano.
} 
Constituição do Império de 1824, com a determinação da criação do Supremo Tribunal de Justiça, instalado em 1829.

Destaque-se que da mesma forma que no Brasil, no caso da Angola, de acordo com Brito Neto (2005), a penetração portuguesa não se deu apenas pela força das armas, mas também em razão da doutrinação das populações por parte da religião dos portugueses, qual seja, o catolicismo, isso considerando que os africanos eram considerados povos bárbaros e sem alma, razão pela qual ocorreu a doutrinação direta por parte da Igreja Católica e do Estado Português, entre 1575 e 1975. A situação formalmente terminou em 1975, com a proclamação da Lei Constitucional, conforme se percebe nas lições do autor e obra citados acima e com lições adiante transcritas:

Essa situação conheceu o seu fim apenas em 1975, ocasião em que o Governo de Angola declarou, através da sua Constituição, a completa separação entre o Estado e a Igreja Católica, no que respeitava à questão da educação dos angolanos e das novas gerações, atribuindo tal responsabilidade à exclusiva competência do Estado, e proclamando a teoria do marxismo-leninismo como o guia teórico para a educação revolucionária das massas populares - Lei Constitucional, proclamada a 11 de novembro de 1975. (BRITO NETO, 2005, p. 19)

Após a Angola tornar-se independente e soberana, em 1975, de acordo com informações colhidas no sítio do Tribunal Supremo da República de Angola (ANGOLA, 2021), as instituições de julgamento foram sucedâneas das existentes à data da Independência Nacional, ressaltando, porém, que a independência da nova República levou à fuga de vários ocupantes dos quadros no país, conforme facilmente pode ser observado na transcrição abaixo, extraída do sítio do Tribunal Supremo de Angola:

[...] com a proclamação da independência e, não obstante o novo contexto Político-Constitucional daí decorrente, bem como a fuga massiva dos quadros do país, da qual os tribunais não foram excepção, o Tribunal da Relação de Luanda continuou funcionando como instância máxima, não apenas da jurisdição comum, mas de todo o sistema judiciário angolano, mantendo assim o seu estatuto, perfil e prestígio;

Contudo, embora se mostrasse e continuasse vertical, útil e prestigiado, com o desenvolvimento socioeconômico do país, o Tribunal da Relação se 
afigurava insuficiente e desajustado à nova realidade social, política e judiciária. Aliás, assinale-se, na década de 80 cresceu a apetência ao estudo do direito e das ciências jurídicas, ou seja, ainda que de modo ténue, iam emergindo quadros angolanos formados na área do direito, muitos dos quais capazes de substituírem as "enciclopédias vivas", com visível longevidade, que eram os juízes daquele tribunal. (ANGOLA, 2021)

Fica claro, pelas afirmações descritas, que o Judiciário da República de Angola foi diretamente atingido com a independência, em 1975, na medida em que vários integrantes das instituições fugiram para Portugal, sendo necessária a reconstrução das estruturas institucionais, inclusive com a formação dos cidadãos angolanos na área do direito, com o fim de ocupar cargos importantes de julgamento, em substituição às "enciclopédias vivas", assim considerados os decanos da magistratura angolana, de acordo com o sítio do Tribunal Supremo.

Nesse contexto de nascimento de Judiciários independentes e vinculados às novas nações, em 1829, com a instalação do Supremo Tribunal de Justiça, no Brasil, e, em 1975, com a continuação do funcionamento do Tribunal da Relação de Luanda, em Angola, surge a necessidade de compreender em que medida os Judiciários do Brasil e de Angola podem aprender com as experiências de ambos, o que se propõe neste estudo, que fará uma análise das histórias, perspectivas e dos desafios da Escola Nacional de Formação e Aperfeiçoamento de Magistrados (Brasil) e do Instituto Nacional de Estudos Judiciários (Angola).

O estudo identificará em que medida as experiências entre as instituições servirão para o crescimento das magistraturas brasileira e angolana, abrindo caminho para o compartilhamento de experiências entre Países Africanos de Língua Oficial Portuguesa - Palop ${ }^{5}$ e os integrantes da Comunidade dos Países de Língua Portuguesa - CPLP, organização intergovernamental a qual inclui, além dos Palops, Brasil, Portugal e Timor-Leste.

Para tanto, inicialmente serão estabelecidos os principais conceitos acerca do tema, com descrição das histórias da Enfam e do Inej, alicerçados em pesquisa bibliográfica. Além disso, por meio da técnica

\footnotetext{
${ }^{5}$ Palop é uma expressão usada para fazer referência aos países africanos que têm a língua portuguesa como oficial. Integram o grupo: Angola, Cabo Verde, Guiné-Bissau, Guiné Equatorial, Moçambique e São Tomé e Príncipe.
} 
de pesquisa documental, serão realizadas consultas à Constituição da República Federativa do Brasil de 1988 (BRASIL, 1988) e à Constituição da República de Angola de 2010 (ANGOLA, 2010), bem como legislações ordinárias, especialmente no que se refere às formações iniciais e continuadas dos magistrados(as) integrantes dos Judiciários brasileiro e angolano.

Em seguida, serão apresentadas as estruturas das escolas judiciais brasileira e angolana, realidade atual de seleção e formação das magistraturas dos dois países, procedendo-se às análises e discussões relativas às informações colhidas, com a apresentação das considerações finais a respeito do tema, levando-se em consideração as perspectivas e os desafios a serem alcançados pelas referidas escolas.

\section{ESCOLA NACIONAL DE FORMAÇÃO E APERFEIÇOA- MENTO DE MAGISTRADOS - ENFAM: ABORDAGEM HIS- TÓRICA E ATUAL}

A criação da Escola Nacional de Formação e Aperfeiçoamento de Magistrados - Enfam foi prevista originalmente na Emenda Constitucional n. 45, de 30 de dezembro de 20046 ${ }^{6}$, e instituída em 30 de novembro de 2006, por meio da Resolução n. 3 do Superior Tribunal de Justiça, ressaltando, porém, que a história da educação judicial no Brasil está ligada à trajetória do Ministro Sálvio de Figueiredo Teixeira, conforme facilmente se percebe com uma leitura atenta às lições constantes no sítio da Enfam, adiante transcritas:

A história da educação judicial no Brasil confunde-se
com a trajetória de um magistrado que, antes de tudo,
era um grande professor. Em seus mais de 40 anos
de magistratura, Sálvio de Figueiredo Teixeira fez da
qualificação do juiz uma de suas principais bandeiras.
Seu grande sonho foi concretizado com a instalação
da Escola Nacional de Formação e Aperfeiçoamento
de Magistrados - Enfam, instituição que carrega
seu nome. (ESCOLA NACIONAL DE FORMAC̃O E
APERFEIÇOAMENTO DE MAGISTRADOS, 2O18a).

\footnotetext{
${ }^{6}$ Art. 105. Compete ao Superior Tribunal de Justiça: [...] Parágrafo único. Funcionarão junto ao Superior Tribunal de Justiça: I - a Escola Nacional de Formação e Aperfeiçoamento de Magistrados, cabendo-Ihe, dentre outras funções, regulamentar os cursos oficiais para o ingresso e promoção na carreira.
} 
O próprio Ministro Sálvio de Figueiredo Teixeira, em exposição denominada A Formação e o Aperfeiçoamento do Magistrado Contemporâneo, após dissertar acerca do Judiciário nos tempos atuais; da Constituição da República; e da insatisfação da sociedade com o modelo de Justiça; da formação e do aperfeiçoamento dos juízes como ponto fundamental na transformação do Judiciário, do sistema brasileiro e do juiz e do processo atual de integração econômica, social e cultural do juiz, enfatiza a necessidade de atenção especial na seleção, formação e no aperfeiçoamento do julgador. Segundo Teixeira (1997, p. 35):

[...] o Judiciário, que neste continente felizmente é qualificado como Poder nas Constituições, não obstante tantas restrições e dificuldades de ordem prática e política, e que muito aquém está das expectativas da sociedade mundial contemporânea, como, aliás, sempre esteve, deve impor-se como verdadeiro Poder, não através de mera retórica, mas de um processo revolucionário do seu modelo histórico tradicional, hermético e arcaico, a realizar uma profunda mudança em sua estrutura e em sua dinâmica, com planejamento científico e vontade política, transformação essa a ter, como um dos seus pontos fundamentais, a adequada seleção, formação e aperfeiçoamento daquele a quem a lei entrega a bela, mas árdua, missão de julgar.

Fica claro, assim, que o verdadeiro Judiciário não deve emanar da mera retórica, segundo o Ministro Sálvio Teixeira (1997), mas deve estar preocupado com a adequada seleção, formação e aperfeiçoamento "daquele a quem a lei entrega a bela, mas árdua, missão de julgar", o que foi iniciado há muito tempo, com base em trabalhos de magistrados anônimos, que certamente foram fundamentais para o atual estágio vivido pelo Judiciário brasileiro, sendo importante ressaltar, para os fins constantes neste estudo, que de fato o Ministro Sálvio sempre foi a grande referência, como bem destacado pela Ministra Eliana Calmon (2007, p. 66), por ocasião da Solenidade de instalação da Escola Nacional de Formação e Aperfeiçoamento de Magistrados - Enfam, realizada em Sessão Solene do Plenário do STJ, em 12 de abril de 2007:

A Enfam, prevista na Emenda Constitucional n. 45, de 30 de dezembro de 2004, hoje se instalando, é fruto de trabalho institucional iniciado na década de 1970; ninguém do Judiciário brasileiro ignora quem primeiro pensou o projeto, misto de sonho e de aventura, e partiu para sua execução: o jovem Juiz mineiro Sálvio de Figueiredo Teixeira. Em 1976, inicia a caminhada em direção à Enfam, ao escrever para a Revista 
Ajuris sobre A Formação e o Aperfeiçoamento dos Magistrados. Com os olhos voltados para a Europa, buscou as recomendações do Primeiro Congresso Internacional de Magistrados, realizado em Roma, em 1958. Encantou-se com uma das recomendações do conclave: a criação de centros de preparação de juízes e de desenvolvimento de pesquisa.

De acordo com Calmon (2007, p. 66-67), o Ministro Sálvio "pesquisou em Portugal e na Alemanha Ocidental as novidades sobre - Poder Judiciário, surgindo daí dois excelentes artigos: Organização Judiciária Portuguesa, em 1973, e A Reforma do Judiciário na Alemanha Ocidental", sendo essas pesquisas as bases sólidas pelas quais passou a construção da Enfam. Leva-se em consideração que o então jovem juiz mineiro, professor de processo civil da Universidade Federal de Minas Gerais, pesquisou em todo o mundo sobre as formas de ingresso de juízes na magistratura, preparação inicial e continuada, tendo inclusive produzido escritos sobre os sistemas de recrutamento na Alemanha Ocidental, na Inglaterra, em Portugal, na França e na Espanha.

Nesse contexto, foi instalada, em 12 de abril de 2007, a Escola Nacional de Formação e Aperfeiçoamento de Magistrados - Enfam, que teve como primeiro diretor-geral o Ministro Nilson Naves, entre 12 de abril de 2007 e 11 de abril de 2009, seguido pelo Ministro Fernando Gonçalves, no período compreendido entre 28 de maio de 2009 e 19 de abril de 2010. A instituição da Enfam foi disciplinada pela Resolução n. 3 de 30 de novembro de 2006, do Superior Tribunal de Justiça. (BRASIL, 2006)

Os demais diretores-gerais foram os seguintes: Ministro Felix Fischer, entre 13 de maio de 2010 e 3 de setembro de 2010; Ministro Cesar Asfor Rocha, entre 4 de setembro de 2010 e 2 de setembro de 2012; Ministra Eliana Calmon, de 4 de setembro de 2012 a 17 de dezembro de 2013; Ministro João Otávio de Noronha, entre 18 de dezembro de 2013 e 16 de dezembro de 2015; Ministro Humberto Martins, de 16 de dezembro de 2015 a 1ํ de setembro de 2016; Ministra Maria Thereza de Assis Moura, entre 2 de setembro de 2016 e 1ํ de setembro de 2018; e Ministro Herman Benjamin, de 5 de setembro de 2018 a 2 de setembro de 2020. (ESCOLA NACIONAL DE FORMAÇÃO E APERFEIÇOAMENTO DE MAGISTRADOS, 2020a)

Ressalte-se que a atual estrutura administrativa da Enfam é formada pelo Ministro Og Fernandes, diretor-geral, com gestão iniciada em 3 de setembro de 2020, também ocupante da presidência do Conselho Superior, tendo como vice-diretor o Ministro Mauro Campbell Marques. 
A atual secretária-geral é a Juíza Federal Cíntia Menezes Brunetta, que tem como assessor Victor Alves Magalhães. (ESCOLA NACIONAL DE FORMAÇÃO E APERFEIÇOAMENTO DE MAGISTRADOS, 2O2Ob)

Atualmente, Jaqueline Aparecida Corrêia de Mello é a secretária executiva e Juliane Bianchi de Lellis e Silva, assessora da Secretaria Executiva. Por sua vez, Marizete da Silva Oliveira, Celi Canovas Feijó Araujo, Sílvio Ferreira e Guilherme Silva Figueiredo ocupam, respectivamente, as coordenações de Planejamento e Avaliação de Ações Pedagógicas, Desenvolvimento de Ações Educacionais, Administração e Finanças e, por fim, de Tecnologia da Informação.

Apresentado o histórico de criação e gestão da Enfam, bem como a estrutura administrativa atualmente em exercício, é importante destacar que, nos termos do art. 93, inciso I, da Constituição da República, o ingresso na carreira, cujo cargo inicial será o de juiz substituto, tem como requisito a aprovação em concurso público de provas e títulos, com a participação da Ordem dos Advogados do Brasil - OAB em todas as suas fases, exigindo-se do bacharel em direito, no mínimo, três anos de atividade jurídica e obedecendo-se, nas nomeações, à ordem de classificação.

Os referidos concursos públicos de provas e títulos, com participação da OAB em todas as fases, são realizados pelos próprios tribunais aos quais os novos juízes serão vinculados, não existindo, nessa fase de recrutamento, a participação da Enfam, ressaltando, porém, que nos termos da alínea c, inciso II, do mesmo art. 93, a promoção de entrância para entrância, pelo critério de merecimento, deve obedecer parâmetros objetivos de produtividade e presteza no exercício da jurisdição e pela frequência e pelo aproveitamento em cursos oficiais ou reconhecidos de aperfeiçoamento.

Com base no dispositivo constitucional referido no parágrafo acima, ao exigir do juiz a frequência e o aproveitamento em cursos oficiais ou reconhecidos de aperfeiçoamento, bem como da disposição constante no art. 93, inciso IV, da mesma Carta Federal, que prevê a necessidade da existência de cursos oficiais de preparação, aperfeiçoamento e promoção de magistrados, constituindo etapa obrigatória do processo de vitaliciamento a participação em curso oficial ou reconhecido por escola nacional de formação e aperfeiçoamento de magistrados, nasce o papel constitucional da Enfam. 
Ressalte-se, também, que o Superior Tribunal de Justiça, por meio da Resolução n. 3 de 30 de novembro de 2006, atribuiu à Escola Nacional de Formação e Aperfeiçoamento de Magistrados, além da realização direta de cursos e eventos, a competência para fiscalizar os cursos oficiais para ingresso e promoção na carreira da magistratura, realizados pelas escolas de magistratura vinculadas aos respectivos tribunais regionais federais e de justiça. Importa destacar, ainda, que o Pleno do Superior Tribunal de Justiça também aprovou o Regimento Interno da Escola, autorizando o diretor-geral a baixar portarias de credenciamento de cursos e de constituição de grupos de trabalho.

Quanto às atribuições da Enfam, destaca-se que o Conselho Superior é formado pelo diretor-geral, pelo vice-diretor, também ministro do Superior Tribunal de Justiça e diretor do Centro de Estudos Judiciários do Conselho da Justiça Federal, por mais dois ministros do Superior Tribunal de Justiça e quatro magistrados, sendo dois da Justiça Federal e dois da Justiça estadual, tendo o referido conselho competência para a edição de resoluções e de instruções normativas.

Cumprindo com sua missão, que é promover, regulamentar e fiscalizar, em âmbito nacional, a formação e o aperfeiçoamento dos magistrados para que a Justiça esteja em sintonia com a demanda social, dentro da visão no sentido de ser referência nacional para as escolas de magistratura como instituição de excelência em ensino e pesquisa, a Enfam vem realizando cursos e promovendo eventos. (ESCOLA NACIONAL DE FORMAÇÃO E APERFEIÇOAMENTO DE MAGISTRADOS, 2018b)

E, dentro da ideia gestada pelo Ministro Sálvio Teixeira, visando à "formação e ao aperfeiçoamento daquele a quem a lei entrega a bela, mas árdua, missão de julgar", a Escola, na gestão do Ministro Herman Benjamim, deu um grande passo para o futuro, com a criação do Programa de Pós-Graduação Profissional em Direito, pela Resolução n. 6 de 7 de agosto de 2019. Isso, após a aprovação pela Coordenação de Aperfeiçoamento de Pessoal de Nível Superior - Capes, durante a 194a reunião do Conselho Técnico-Científico da Educação Superior/ CTC-ES e parecer do Conselho Nacional de Educação - Câmara de Educação Superior/CNE/CES n. 350/2020.

O Mestrado Profissional da Enfam tem por foco principal a gestão judiciária e o tratamento de conflitos e é guiado pela busca de efetivo aprimoramento do sistema de justiça e da prática jurisdicional, sendo permeado por um eixo transversal comum que contempla a ética, 
a integridade e a inovação (ESCOLA NACIONAL DE FORMAÇÃO E APERFEIÇOAMENTO DE MAGISTRADOS, 2019) e teve suas atividades iniciadas em momento histórico, no dia 11 de setembro de 2020, com a abertura pelos Ministros Herman Benjamim e Og Fernandes, respectivamente coordenador-geral do programa e diretor-geral da Enfam.

Ao destacar o grande interesse dos participantes brasileiros e de outros países lusófonos, como Angola e Moçambique, o Ministro Benjamim ressaltou que o Mestrado Profissional "é um programa pioneiro no mundo", tendo enfatizado que o objetivo é "dar ao povo brasileiro o melhor retorno possível, demonstrando que esse não é um investimento em nós, mas na própria jurisdição". Ao final, o Ministro Herman fez questão de deixar claro que o objetivo é tratar a produção acadêmica como um ponto importante, na medida em que as pesquisas realizadas no âmbito do Mestrado Profissional certamente serão aproveitadas pela revista da Enfam, publicação dirigida pela ministra Maria Thereza de Assis Moura. (MINISTROS, 2020)

$\mathrm{Na}$ abertura do Mestrado Profissional, ao destacar o momento histórico, o atual diretor-geral da Enfam foi enfático em afirmar que "a história do Poder Judiciário e da magistratura, não só brasileira, mas dos países de língua portuguesa, passa por nós e diz: sejam bem-vindos" (MINISTROS, 2020), destacando que essa expansão dos conhecimentos produzidos pela Enfam pelo mundo é realidade, na medida em que a primeira turma de mestrandos tem entre os seus alunos o Juiz Desembargador Artur Gunza, diretor-geral do Instituto Nacional de Estudos Judiciários de Angola - Inej.

Por fim, atendendo ao importante registro histórico para o qual se propõe este estudo, é imperioso listar o primeiro corpo docente do mestrado profissional do Programa de Pós-Graduação da Escola Nacional de Formação e Aperfeiçoamento de Magistrados: Adriana Ramos de Melo, André Augusto Salvador Bezerra, Antônio César Bochenek, Carlos Henrique Borlido Haddad, Elayne da Silva Ramos Cantuária, Fábio César dos Santos Oliveira, Fabrício Castagna Lunardi, Fernando Braga Damasceno, Frederico Augusto Leopoldino Koehler, José Marcos Lunardelli, Luciane Amaral Corrêa Münch, Luíza Vieira Sá de Figueiredo, Marcus Vinícius Pereira Júnior, Priscilla Pereira Costa Corrêa, Roberto 
Portugal Bacellar, Roger Raupp Rios, Rosimeire Ventura Leite, Samuel Meira Brasil Júnior e Taís Schilling Ferraz?

\section{INSTITUTO NACIONAL DE ESTUDOS JUDICIÁRIOS - INEJ: ABORDAGEM HISTÓRICA E ATUAL}

A compreensão histórica do Instituto Nacional de Estudos Judiciários - Inej deve partir da informação de que o ensino do direito após a independência da Angola, em 1975, teve início apenas no ano de 1979, com a abertura da Faculdade de Direito da Universidade Agostinho Neto, por Despacho Ministerial n. 32.779, e criação confirmada pelo Decreto n. 152/780, de 29 de setembro de 1980, do Conselho de Ministros. Assim, os primeiros angolanos que concluíram sua formação no próprio território angolano terminaram o curso de licenciatura em direito em 1984, com destaque para o fato de que, após o $3^{\circ}$ ano do curso, o estudante é considerado bacharel, completando sua formação como licenciado em direito apenas após o 5a ano de curso.

A informação constante no parágrafo anterior é importante para contextualizar o momento histórico vivido em Angola, antes da independência, na medida em que o curso de direito e o respectivo acesso à magistratura, no referido período, eram possíveis apenas para membros de determinadas famílias integrantes da elite social, com preferência de homens brancos portugueses em detrimento de homens e mulheres negros angolanos.

O homem negro era considerado inferior, podendo, ao reunir algumas condições, ser considerado assimilado e, por consequência, integrar a magistratura. Tal condição, porém, partia do pressuposto de que podiam ser dirigidos e enquadrados por europeus, conforme esclareceu:

Se Oliveira Martins definia o homem negro como um
tipo antropológico inferior, Marcello Caetano, antigo
ministro das colónias e primeiro-ministro depois da
morte de Salazar, definia os africanos das colónias
portuguesas nestes termos, segundo a tipologia por
ele elaborada: os negros em Africa devem ser dirigidos
e enquadrados por europeus e são indispensáveis

\footnotetext{
7 https://www.enfam.jus.br/wp-content/uploads/2021/04/Docentes-Mestrado.pdf. Acesso em: 23 maio 2021.

${ }^{8}$ Número especial Comemorativo do XXXV Aniversário da Faculdade de Direito e do XXX Aniversário da 1ำ Licenciatura em Direito, 1. ed., abril de 2015.
} 
como auxiliares da colonização: a) ter 18 anos; b) falar correctamente o português; c) exercer uma profissão, um ofício ou um emprego que dê recursos suficientes para o seu sustento e o da sua família; d) ter uma vida aceitável, usos, costumes e hábitos portugueses sem os quais não se pode aplicar o direito público e privado português. (Ngonda, 2020, p. 38)

Pela informação acima, fica claro que o homem negro africano era considerado um ser inferior, o que lhe afastou, naturalmente, da ocupação de funções importantes, como o exercício da magistratura, e gerou um grande prejuízo para Angola, após a independência, na medida em que grande parte daqueles que exerciam a magistratura abandonaram o país, ficando a Angola carente de pessoas capazes de integrar os quadros nacionais no que se refere à administração da justiça.

Nesse contexto, é importante mencionar que, após a independência, em Angola, o exercício da magistratura passou a ser função exclusiva de cidadãos nacionais, estando tal requisito atualmente disciplinado no art. 41, n. 1/a, do Estatuto dos Magistrados Judiciais e do Ministério Público, aprovado pela Lei n. 7, de 29 de abril de 1994. (ANGOLA, 1994)

Depois da independência e perante a escassez de quadros, o Estado angolano flexibilizou os critérios de seleção e admissão de magistrados e membros do Ministério Público, introduzindo na lei critérios para que todos concorressem em igualdade de circunstâncias, com base nos princípios da igualdade e da não discriminação, nos termos do art. 23, da Constituição da República de Angola, levando em consideração que os tribunais necessitavam funcionar, diante do anseio de se fazer justiça para a proteção dos direitos, liberdades e garantias dos cidadãos, com os recursos humanos disponíveis.

Na prática, após a independência de 1975, a primeira opção para integrar os quadros da magistratura angolana, quase que de forma emergencial, foi eleger aqueles que tinham experiência como oficiais de Justiça, com a categoria de secretários judiciais, escrivães, ajudantes, entre outros, para assumirem a função de juízes e procuradores. (ANGOLA, 1994)

Enquanto isso, o Estado angolano incrementou o ensino de direito na Faculdade de Direito da Universidade Agostinho Neto, única existente na época, e passou a aproveitar os estudantes com o $3^{\circ}$ ano do curso concluído, que vieram reforçar o sistema de justiça, isso com base na 
previsão legal estabelecida no art. 41, n. 2, do Estatuto dos Magistrados Judiciais e do Ministério Público, que assim estabelece:

Enquanto não houver cidadãos licenciados em direito em número suficiente, podem ser nomeados para exercer a Magistratura: a) nos tribunais provinciais e junto deles, os estudantes de direito, habilitados com o $3^{\circ}$ ano; b) nos tribunais municipais e junto deles, os estudantes de direito ou os cidadãos habilitados com a $12^{a}$ classe ou equivalente. (ANGOLA, 1994, p. 163)

Dentro dessa realidade de dificuldade da existência de cidadãos aptos ao exercício da magistratura, foi sendo formado o Judiciário em Angola, até que o legislador consagrou no n. 1, do art. 42, do Estatuto dos Magistrados Judiciais e do Ministério Público, aprovado pela Lei n. 7/1994, a necessidade de aprovação em concurso público para o ingresso nas magistraturas judicial e do Ministério Público, que fazem parte da mesma previsão legal, ressaltando que a primeira convocação deve ser para ocupação em instâncias de categoria inferior, nos termos do n. 2, do mesmo diploma legal. Seguem as transcrições, para facilitar a compreensão:
ARTIGO 42
(Modo de Ingresso)
1. $O$ ingresso nas Magistraturas Judicial e do Ministério Público faz-se mediante concurso público de provimento e condicionado ao aproveitamento em posterior curso de formação e ou estágio específico.
2. A primeira nomeação faz-se para instâncias de categoria inferior. (ANGOLA, 1994, p. 163)

É importante ressaltar que o ingresso na magistratura de Angola, mesmo após a exigência de concurso público, passou a ser efetivado mediante a apresentação de documentos, sem a realização de testes. A formação, portanto, era no próprio ambiente de trabalho e, excepcionalmente, um ou outro juiz era selecionado para uma formação no exterior, como no Centro de Estudos Judiciários - CEJ, localizado em Portugal, que tem a seguinte missão, de acordo com o seu sítio:

A principal missão do Centro de Estudos Judiciários é a formação de magistrados. Neste âmbito, compete ao CEJ assegurar a formação, inicial e contínua, de magistrados judiciais e do Ministério Público para os tribunais judiciais e para os tribunais administrativos e fiscais. 
Em matéria de formação de magistrados ou de candidatos à magistratura de países estrangeiros, compete ao CEJ assegurar a execução de atividades formativas, no âmbito de redes ou outras organizações internacionais de formação de que faz parte, e de protocolos de cooperação estabelecidos com entidades congéneres estrangeiras, em especial, de países de língua portuguesa. Compete-lhe ainda assegurar a execução de projetos internacionais de assistência e cooperação na formação de magistrados e acordos de cooperação técnica em matéria judiciária, celebrados pelo Estado português. (CENTRO DE ESTUDOS JUDICIÁRIOS, 2020)

Ao analisar a missão do Centro de Estudos Judiciários de Portugal, observa-se a referência expressa na formação de magistrados ou candidatos à magistratura de países estrangeiros, ficando clara a missão de fortalecer a magistratura de outros países, especialmente os de língua portuguesa, como ocorreu com a magistratura angolana.

Nessa perspectiva, em 1997, foi criado, junto ao Ministério da Justiça, um gabinete designado por Comissão de Bolsas de Formação para Magistrados, composto por seis funcionários, incluindo o diretorgeral. O gabinete evoluiu e posteriormente transformou-se no Instituto Nacional de Estudos Judiciários - Inej, com base no Estatuto Orgânico, aprovado pelo Decreto n. 46, de 13 de setembro de 2002, e ganhou o status de Instituto Público. Provisoriamente, foi instalado no edifício do Instituto Nacional de Estatística.

Com o decorrer do tempo, o diploma supracitado, ou seja, o Decreto n. 46, de 13 de setembro de 2002, mostrou-se desajustado à realidade, razão pela qual foi revogado pelo Decreto Presidencial n. 84, de 5 de maio de 2015, que consagra o Inej como pessoa coletiva pública do setor administrativo, com missão de assegurar a formação dos quadros necessários ao exercício da atividade jurisdicional e das demais funções específicas no domínio da justiça, dos registos e do notariado, da identificação civil e criminal, da defesa pública e outras áreas do sistema judiciário, nos termos do art. 4º, do Estatuto Orgânico do Inej.

Ao Instituo Nacional de Estudos Judiciários, foi atribuída também a competente autonomia administrativa, financeira, patrimonial e científica para que possa garantir o cumprimento da sua missão de maneira satisfatória, ressaltando que atualmente a seleção para o ingresso na magistratura de Angola é feita pelo instituto, nos termos dos arts. 36 e 38, adiante transcritos: 
CAPÍTULO VI

Admissão ao Concurso Público de Ingresso na Magistratura

ARTIGO 36

(Admissibilidade e Ingresso)

São requisitos de admissão ao concurso público de ingresso à Magistratura Judicial ou do Ministério Público os definidos nos respectivos Estatutos.

ARTIGO 37

(Vagas)

No mês de janeiro de cada ano civil, o Diretor-Geral do Inej deve informar ao Presidente da Comissão de Coordenação, após consulta aos respectivos Conselhos Superiores das Magistraturas Judicial e do Ministério Público, o número previsível de vagas abertas para ingresso. (ANGOLA, 2015, p. 1749)

E, para os fins do presente estudo, bem como para compreender as funções do Inej, é imperioso ressaltar que o chamado "júri", ou comissão de concurso para o ingresso na magistratura em Angola, é "proposto pelo diretor do Inej e nomeado pelo titular do órgão responsável pelo Sector da Justiça e dos Direitos Humanos", sendo "composto por cinco membros, entre os quais um magistrado judicial e um magistrado do Ministério Público propostos pelos respectivos conselhos superiores, podendo os demais pertencer a outras áreas da ciência e da cultura", tudo nos termos do art. 39, do Decreto Presidencial n. 84/2015.

Quanto à estrutura de gestão, a direção-geral do Instituto Nacional de Estudos Judiciários é em regra exercida de forma rotativa, entre o magistrado judicial e o Ministério Público, tendo, desde a sua criação, em 13 de setembro de 2002, o cargo sido ocupado pelo representante da magistratura judicial, Augusto Escrivão, entre 1997 e 2004; pelos representantes da magistratura do Ministério Público, Maria Paula Ramos Furtado, Norberto Mosés Moma Capeça e Vanda das Dores Miguel de Lima, respectivamente nas gestões 2004-2008, 2009-2014, 2015-2018.

Em seguida, a gestão passou a ser exercida pela representante da magistratura judicial, Juíza Conselheira Jubilada Luzia Bebiana de Almeida Sebastião, estando em exercício atualmente na direção-geral do Inej o Juiz Desembargador Artur Domingos Gunza, e as respectivas direções-gerais adjuntas de Estudos e Investigação Judiciária, de Estágios e Capacitação para a Magistratura do Ministério Público e de Estágios e Capacitação para a Magistratura Judicial, ocupadas respectivamente por Adélia Maria Pires da Conceição de Carvalho, António José Sebastião e João Paulo da Silva Morais. 
Por fim, acerca do Inej, pela atual fase de desenvolvimento da magistratura em Angola, é importante destacar que a cooperação internacional é verdadeiramente um instrumento essencial para potencializar a capacidade da magistratura angolana, visando possibilitar a troca de conhecimentos, aprimorando as competências técnicas capazes de fortificar as instituições.

Nesse particular, destaca-se o Centro de Estudos Jurídicos e Judiciários de Moçambique que, em distintos momentos, acolheu em sede de formação, magistrados angolanos; o Centro de Estudos Judiciários de Portugal; a Escola de Formação de Magistrados de São Paulo/Brasil; e a Escola Nacional de Aperfeiçoamento e Formação de Magistrados, que durante o seu pioneiro Mestrado Profissional, acolheu o Juiz Desembargador Artur Domingos Gunza, como discente na turma histórica, que certamente será referência em todo o mundo, quando forem narradas as conquistas históricas da magistratura no mundo.

\section{CONCLUSÃO}

A análise da origem do Brasil e de Angola, antigas colônias portuguesas, aproxima as magistraturas brasileira e angolana, ressaltando que a aproximação das referidas nações com Portugal, no período das Grandes Navegações, ocorreu em períodos similares, por volta de 1500. Assim, os órgãos de julgamento nas então colônias de Portugal eram totalmente vinculados à metrópole, com a diferença de que o Judiciário brasileiro adquiriu autonomia há mais tempo que o angolano, considerando que as independências ocorreram em períodos totalmente distintos, em 1822, no Brasil, e em 1975, em Angola.

Assim, os contextos históricos de formação dos judiciários nas novas nações, em 1829, com a instalação do Supremo Tribunal de Justiça, no Brasil, e com a continuação do funcionamento do Tribunal da Relação de Luanda, em Angola, em 1975, são de fundamental importância para a compreensão no desenvolvimento dos referidos judiciários, na medida em que o brasileiro foi formado, inicialmente, sem a presença de grandes conflitos, o que não ocorreu em Angola, onde vários integrantes do Judiciário fugiram para Portugal, por ocasião da independência, sendo necessária a reconstrução das estruturas institucionais, inclusive com a formação dos cidadãos angolanos na área do direito.

Portanto, a diferença de aproximadamente 153 anos entre a independência do Brasil e de Angola reflete diretamente no atual 
desenvolvimento e consolidação da magistratura brasileira, que hoje é formada por juízes(as) selecionados(as) por meio de concurso público, de provas e títulos, nos termos do art. 93, inciso I, da Constituição da República de 1988, com a exigência, a partir da Emenda Constitucional n. 45/2004, de comprovação de, no mínimo, três anos de atividade jurídica como requisito para a ocupação do cargo de juiz substituto.

Em Angola, devido à escassez de cidadãos em condições de exercer o cargo por ocasião da independência, em 1975, foram mitigados os requisitos para ingresso no cargo, com destaque para o fato de que, mesmo após o disposto no n. 1 , art. 42, do Estatuto dos Magistrados Judiciais e do Ministério Público, aprovado pela Lei n. 7/1994, a exigência de concurso público era apenas no sentido de apresentação de documentos, sem a realização de testes para o ingresso, com a formação no próprio ambiente de trabalho.

Nesse contexto, é imprescindível enfatizar que a história da educação judicial no Brasil está ligada à trajetória do Ministro Sálvio de Figueiredo Teixeira, estudioso da seleção e formação da magistratura no mundo, tendo em seus estudos concluído que o verdadeiro Judiciário não deve emanar da mera retórica, mas deve estar preocupado com a adequada seleção, formação e aperfeiçoamento "daquele a quem a lei entrega a bela, mas árdua, missão de julgar".

E, dessa necessidade e sonho pelo fortalecimento da magistratura do Ministro Sávio Teixeira, nasceu a Escola Nacional de Formação e Aperfeiçoamento de Magistrados - Enfam, instalada em Sessão Solene do Plenário do STJ, em 12 de abril de 2007. E, com justiça, a Enfam leva o nome do Ministro Sálvio de Figueiredo Teixeira, que dedicou mais de 40 anos da sua vida à magistratura, lecionou processo civil na Universidade Federal de Minas Gerais e pesquisou em todo o mundo sobre as formas de ingresso de juízes na magistratura, preparação inicial e continuada, tendo inclusive produzido escritos sobre os sistemas de recrutamento na Alemanha Ocidental, Inglaterra, Portugal, França e Espanha.

Nessa perspectiva, é forçoso afirmar que a Enfam tem como escopo promover e fiscalizar cursos oficiais ou reconhecidos de aperfeiçoamento, nos termos do art. 93, inciso IV, da mesma Carta Federal, visando à preparação, ao aperfeiçoamento e à promoção de magistrados, constituindo etapa obrigatória do processo de vitaliciamento a participação dos magistrados. 
Ressalte-se, também, que o Superior Tribunal de Justiça, por meio da Resolução n. 3/2006, atribuiu à Escola Nacional de Formação e Aperfeiçoamento de Magistrados, além da realização direta de cursos e eventos, a competência para fiscalizar os cursos oficiais para ingresso e promoção na carreira da magistratura, realizados pelas escolas de magistratura vinculadas aos respectivos tribunais regionais federais e de justiça. Por sua vez, o Pleno do Superior Tribunal de Justiça aprovou ainda o Regimento Interno da Escola, autorizando o diretor-geral a baixar portarias de credenciamento de cursos e de constituição de grupos de trabalho.

Po outro lado, o Instituto Nacional de Estudos Judiciários de Angola, de acordo com o Decreto Presidencial n. 84/2015, tem como missão participar diretamente da seleção de novos magistrados angolanos, com destaque, também, para a missão de assegurar a formação dos quadros necessários ao exercício da atividade jurisdicional e das demais funções específicas no domínio da justiça, dos registos e do notariado, da identificação civil e criminal, da defesa pública e de outras áreas do sistema judiciário.

Compreendidos os aspectos históricos e peculiaridades da Escola Nacional de Formação e Aperfeiçoamento de Magistrados - Enfam e do Instituto Nacional de Estudos Judiciários - Inej, esta pesquisa encontrou vários pontos em comum entre as duas instituições, destacando que, juntas, com a internacionalização das ações das duas escolas, o grande objetivo do Ministro Sálvio Teixeira está sendo alcançado, na medida em que as ações desenvolvidas pelas referidas escolas estão materializando a adequada seleção, formação e aperfeiçoamento "daquele a quem a lei entrega a bela, mas árdua, missão de julgar". 


\section{REFERÊNCIAS}

ANGOLA. Assembleia Nacional. Lei n. 7/94 de 29 de abril. Luanda, 1994. Disponível em: http://tribunalsupremo.ao/wp-content/ uploads/2018/05/lei-7-94-estatuto-dos-magistrados-judiciais-e-doministerio-publico.pdf. Acesso em: 23 maio 2021.

ANGOLA. Constituição da República Angolana de 2010. Luanda, 2010. Disponível em: https://acjr.org.za/resource-centre/Constituicao_da_ Republica_de_Angola.pdf. Acesso em: 22 maio 2021.

ANGOLA. Decreto Presidencial n. 84/15 de 5 de maio. Luanda, 2015. Disponível em: https://inej.ao/wp-content/uploads/2021/02/2-EstatutoOrganico-do-INEJ.pdf. Acesso em: 20 maio 2021.

ANGOLA. Tribunal Supremo. História do Tribunal Supremo da República de Angola. Luanda, [2021]. Disponível em: https:// tribunalsupremo.ao/sobre-o-tribunal/historia. Acesso em: 22 maio 2021.

BRASIL. Conselho Nacional de Justiça. Proname: gestão de memória do poder judiciário. Brasília, [2021]. Disponível em: https://www.cnj.jus.br/ programas-e-acoes/gestao-documental-e-memoria-proname/gestaode-memoria/memoria-do-poder-judiciario-historia-e-linha-do-tempo. Acesso em: 22 maio 2021.

BRASIL. [Constituição (1988)]. Constituição da República Federativa do Brasil. Brasília, DF: Senado Federal: Centro Gráfico, 1988.

BRASIL. Emenda Constitucional n. 45, de 30 de dezembro de 2004. Altera dispositivos dos arts. 5o, 36, 52, 92, 93, 95, 98, 99, 102, 103, 104, 105, 107, 109, 111, 112, 114, 115, 125, 126, 127, 128, 129, 134 e 168 da Constituição Federal, e acrescenta os arts. 103-A, 103B, 111-A e 130-A, e dá outras providências. Brasília, 2004. Disponível em: http://www. planalto.gov.br. Acesso em: 22 maio 2021.

BRASIL. Superior Tribunal de Justiça (STJ). Resolução n. 3, de $\mathbf{3 0}$ de novembro de 2006. Dispõe sobre a instituição da Escola Nacional de Formação e Aperfeiçoamento de Magistrados e dá outras providências. Brasília, 2006. Disponível em: https://bdjur.stj.jus.br/jspui/ handle/2011/8339. Acesso em: 22 maio 2021.

BRITO NETO, Manuel. História e educação em Angola: do colonialismo ao Movimento Popular de Libertação de Angola (MPLA). Campinas: [S.n], 2005. Disponível em: http://www.repositorio.unicamp.br/bitstream/ REPOSIP/252396/1/BritoNeto_Manuel_D.pdf. Acesso em: 22 maio 2021. 


\section{CALMON, Eliana. Homenagem durante a instalação da}

Enfam. Brasília, 2007. Disponível em: https://www.stj.jus. $\mathrm{br} /$ publicacaoinstitucional/index.php/coletanea/author/ proofGalleyFile/1641/1567. Acesso em: 23 maio 2021.

CENTRO DE ESTUDOS JUDICIÁRIOS. Missão. Lisboa, 2020. Disponível em: http://www.cej.mj.pt/cej/conheca-cej/missao.php. Acesso em: 23 maio 2021.

ESCOLA NACIONAL DE FORMAÇÃO E APERFEIÇOAMENTO DE MAGISTRADOS (ENFAM). Ex-diretores-gerais. Brasília, 2020a.

Disponivel em: https://www.enfam.jus.br/institucional/ex-diretoresgerais/. Acesso em: 23 maio 2021.

ESCOLA NACIONAL DE FORMAÇÃO E APERFEIÇOAMENTO DE MAGISTRADOS (ENFAM). Idealizador da escola. Brasília, 2018a.

Disponível em: https://www.enfam.jus.br/institucional/idealizador-daescola/. Acesso em: 23 maio 2021.

ESCOLA NACIONAL DE FORMAÇÃO E APERFEIÇOAMENTO DE MAGISTRADOS (ENFAM). Missão e visão. Brasília, 2018b. Disponível em: https://www.enfam.jus.br/institucional/missao-e-visao-2/. Acesso em: 23 maio 2021.

ESCOLA NACIONAL DE FORMAÇÃO E APERFEIÇOAMENTO DE MAGISTRADOS (ENFAM). Pós-graduação. Brasília, 2019. Disponível em: https://www.enfam.jus.br/ensino/programa-de-pos-graduacaoprofissional-em-direito. Acesso em: 23 maio 2021.

ESCOLA NACIONAL DE FORMAÇÃO E APERFEIÇOAMENTO DE MAGISTRADOS (ENFAM). Quem somos. Brasília, 2020b. Disponível em: https://www.enfam.jus.br/institucional/quem-somos/. Acesso em: 23 maio 2021.

ESCOLA NACIONAL DE FORMAÇÃO E APERFEIÇOAMENTO DE MAGISTRADOS (ENFAM); ANGOLA. Ministério da Justiça e dos Direitos Humanos. Instituto Nacional de Estudos Jurídicos. Protocolo de Cooperação n. 003/2018. Brasília, 2018. Disponível em: https://www. enfam.jus.br/wp-content/uploads/2018/12/PROTO-2018_O3-ENFAMINEJ.pdf. Acesso em: 6 fev. 2021. 
MINISTROS Herman Benjamin e Og Fernandes abrem curso de mestrado profissional da Enfam em direito e Poder Judiciário. STJ Notícias, Brasília, 2020. Disponível em: https://www.stj.jus.br/sites/ portalp/Paginas/Comunicacao/Noticias/11092020-Ministros-HermanBenjamin-e-Og-Fernandes-abrem-curso-de-mestrado-profissional-daEnfam-em-direito-e-Poder-Judiciar.aspx. Acesso em: 23 maio 2021.

MPLA. História geral de Angola. Argélia: Edições Afrontamento, 1965.

NGONDA, Lucas. Descolonização, luta pelo poder e a construção de uma nova sociedade. Luanda: Mayamba, 2020.

TEIXEIRA, Sálvio de Figueiredo. A formação e o aperfeiçoamento do magistrado contemporâneo. Revista dos Tribunais, São Paulo, v. 86, n. 746, p. 28-35, dez. 1997. Disponível em:https://bdjur.stj.jus.br/jspui/ bitstream/2011/10167/formacao_aperfeicoamento_magistrado_teixeira. pdf. Acesso em: 20 maio 2021.

VIEIRA, Pedro Almeida. Assim se pariu o Brasil. S. Pedro de Estoril, Portugal: Saída de Emergência, 2015. 